\title{
Reproducibility of the serum lipid response to coffee oil in healthy volunteers
}

\author{
Mark V Boekschoten*, Mariëlle F Engberink, Martijn B Katan and \\ Evert G Schouten
}

Address: Division of Human Nutrition \& Epidemiology, Wageningen University, The Netherlands

Email: Mark V Boekschoten* - Mark.Boekschoten@wur.nl; Mariëlle F Engberink - Marielle.Engberink@wur.nl; Martijn B Katan - wcfs1@wur.nl; Evert G Schouten - Evert.Schouten@wur.nl

* Corresponding author

Published: 04 October 2003

Nutrition Journal 2003, 2:8
Received: 18 September 2003

Accepted: 04 October 2003

This article is available from: http://www.nutritionj.com/content/2/I/8

(C) 2003 Boekschoten et al; licensee BioMed Central Ltd. This is an Open Access article: verbatim copying and redistribution of this article are permitted in all media for any purpose, provided this notice is preserved along with the article's original URL.

\begin{abstract}
Background: Humans and animals show a certain consistency in the response of their serum lipids to fat-modified diets. This may indicate a genetic basis underlying this response. Coffee oil might be used as a model substance to investigate which genes determine differences in the serum lipid response. Before carrying out such studies our objective was to investigate to what extent the effect of coffee oil on serum lipid concentrations is reproducible within subjects.
\end{abstract}

Methods: The serum lipid response of 32 healthy volunteers was measured twice in separate fiveweek periods in which coffee oil was administered $(69 \mathrm{mg}$ cafestol / day).

Results: Total cholesterol levels increased by $24 \%$ in period I (range:0;52\%) and I $8 \%$ in period 2 (I;48\%), LDL cholesterol by $29 \%(-9 ; 7 \mid \%)$ and $20 \%(-12 ; 57 \%)$, triglycerides by $66 \%(16 ; 175 \%)$ and $58 \%(-13 ; 202 \%)$, and HDL cholesterol did not change significantly: The range of the HDL response was $-19 ; 25 \%$ in period $I$ and $-20 ; 33 \%$ in period 2 .

The correlation between the two responses was $0.20(95 \% \mathrm{Cl}-0.16,0.5 \mathrm{I})$ for total cholesterol, 0.16 $(95 \% \mathrm{Cl}-0.20,0.48)$ for $\mathrm{LDL}, 0.67(95 \% \mathrm{Cl} 0.42,0.83)$ for $\mathrm{HDL}$, and $0.77(95 \% \mathrm{Cl} 0.56,0.88)$ for triglycerides.

Conclusions: The responses of total and LDL cholesterol to coffee oil were poorly reproducible within subjects. The responses of HDL and triglycerides, however, appeared to be highly reproducible. Therefore, investigating the genetic sources of the variation in the serum-lipid response to coffee oil is more promising for $\mathrm{HDL}$ and triglycerides.

\section{Background}

The effect of dietary changes on serum lipid levels differs significantly between individuals [1-5]. The differences in response may be caused by variation in genes regulating serum lipid levels [6-8]. Identification of genes regulating the lipid response may help to clarify the mechanism by which diet raises serum lipid levels. It also might provide leads for dietary and pharmacotherapeutical means of lowering serum cholesterol. Cafestol, a cholesterol-raising substance in coffee oil, can be used to study lipid 
metabolism and the genes involved [9-11] because it greatly affects serum lipid levels in humans [9-11]. Therefore, coffee oil can be used to affect serum lipid levels without the need to provide a fully controlled diet. The effect of coffee oil on the expression of genes in humans, however, is difficult to study in relevant tissues like liver or intestinal epithelium.

An alternative approach is to study the response of serum lipids to coffee oil in individuals having different genotypes of certain polymorphic candidate genes. For such an approach to succeed, two conditions must be met: First, the response of lipids to coffee oil should be sufficiently different between persons; if this is not the case, the effect of the candidate polymorphisms on the response may be too small to be detected in a study. Second, the individual response of lipids to coffee oil should be sufficiently reproducible; otherwise an efficient study of the effects of genetic factors may not be possible. If these two conditions are not met, the study of individual polymorphisms is not feasible.

The present study was therefore designed to assess the reproducibility and the reliability of the response to coffee oil in subjects from the general population.

\section{Methods \\ Subjects}

Subjects were recruited among the student population of Wageningen, a university town in the Netherlands.

Fifty-one men and women were recruited; their health was assessed by means of a questionnaire, and blood and urine testing. We used the following eligibility criteria: serum cholesterol $<8 \mathrm{mmol} / \mathrm{l}$, serum triglycerides $<3.0$ $\mathrm{mmol} / \mathrm{l}$, no glucosuria, normal liver enzyme activities in serum, no use of medication with effects on serum lipids, and no history of gastrointestinal or liver disease. Because coffee oil can increase the activities of the liver enzymes alanine aminotransferase (ALAT) and aspartate aminotransferase (ASAT) $[9,12]$. We measured liver enzyme activities before and during the study. One subject was excluded at baseline because of liver enzyme activity above the upper limit. Consequently, fifty subjects were enrolled in the study.

During the study five subjects withdrew cooperation: three subjects suffered from stomach complaints, one went abroad, and one had a gastrointestinal infection. Another 13 subjects had to be excluded during the study because their serum activities of ALAT and ASAT exceeded previously determined boundaries. These boundaries were 2.7 times the upper limit of normal for ALAT and 1.5 times the upper limit of normal for ASAT.
Thus, thirty-two subjects completed the study. The Medical Ethical Committee of Wageningen University and Research Centre approved the study. Each volunteer gave an informed consent.

\section{Study design}

The response of serum lipids to coffee oil consumption was measured twice in each subject.

Subjects first entered a run-in period of three weeks in which they received four placebo capsules daily. Placebo capsules contained $0.25 \mathrm{ml}$ sunflower oil and $0.25 \mathrm{ml} \mathrm{saf-}$ flower oil per capsule.

After the run-in period subjects took four coffee-oil capsules a day ( $2 \mathrm{ml}$ oil per day) for a five-week period. The coffee-oil capsules provided $69 \mathrm{mg}$ cafestol and $51 \mathrm{mg}$ of kahweol per day. The run-in and the coffee-oil period together constituted period 1 . The change in the level of serum lipids from the end of run-in period 1 to the end of coffee-oil period 1 was defined as response 1 . This first coffee-oil period was followed by a three-week wash-out period in which no capsules were supplied.

After the wash-out period subjects repeated the first two periods: a three-week run-in period (run-in 2) and a fiveweek coffee-oil period (coffee-oil period 2). See figure 1 for a diagram of the study design.

Subjects were asked to maintain their lifestyles and dietary habits for the duration of the study. They reported changes in diet, smoking, physical activity, use of medication, illness, and the number of capsules taken daily in diaries.

We measured body weight at the beginning of the run-in and coffee-oil periods and at the end of the coffee-oil periods.

\section{Blood lipids}

Blood samples were taken from subjects who had fasted overnight on four separate days in the last two weeks of the run-in and coffee-oil periods. In total, each subject had blood drawn 19 times. In 16 samples serum lipid levels were determined. All 16 samples were analysed within one run. Total cholesterol and triglycerides were measured with Cholesterol Flex and Triglycerides Flex reagent cartridge (Dade Behring); HDL was measured with the Liquid $\mathrm{N}$-geneous HDL assay (Instruchemie BV.); LDL cholesterol concentrations were calculated [13].

\section{Liver enzymes}

To measure liver enzyme activities, we took additional blood samples during the second week of the two coffeeoil periods and within two months after the experiment. 


\begin{tabular}{|l|l|c|l|l|c|}
\hline Screening & Run-in 1 & Coffee-oil 1 & Wash-out & Run-in 2 & Coffee-oil 2 \\
\hline
\end{tabular}

Figure I

Diagram of the study design. The week number is indicated above. Black arrows indicate blood sampling days. Dashed arrows indicate blood sampling days for determination of liver enzyme activities.

In these samples activities of ALAT (Alanine Aminotransferase Flex reagent cartridge, Dade Behring) and ASAT (Aspartate Aminotransferase Flex reagent cartridge, Dade Behring) were measured at $37^{\circ} \mathrm{C}$. Liver enzyme activities are given in multiples of the upper limit of normal because activities vary with the temperature used when determining liver enzyme activities in different laboratories. The upper limits of normal in this laboratory are 45 IU/l for ALAT and $41 \mathrm{IU} / \mathrm{l}$ for ASAT. When ALAT levels exceeded the 2.7 times upper limit of normal or ASAT levels exceeded 1.5 times upper limit of normal, subjects were taken off coffee-oil treatment. These boundaries were based on what is considered a mild increase in liver enzymes activities in plasma $[9,12]$.

\section{Statistical analysis}

A subject's response to coffee-oil in period 1 was defined as the mean serum lipid level at the end of coffee-oil period 1 minus the mean at the end of run-in period 1 . The mean level of serum lipids in a period is calculated as the mean of the four repeated measurements in each period. The response in period 2 was calculated in the same way.

We calculated within and between person standard deviations (SD's) of serum lipid levels in the four periods and the two responses. The four periods are: run-in 1, run-in 2, coffee-oil 1 and coffee-oil 2.

We used the following definitions in our calculations:

$\mathrm{SD}_{\text {total }}$ of run-in 1: $\mathrm{SD}$ of the mean serum lipid level of 32 subjects in run-in 1.
$\mathrm{SD}_{\text {total }}$ response: $\mathrm{SD}$ of the mean serum lipid response of 32 subjects. The mean response is calculated from the two responses.

$\mathrm{SD}_{\text {within }}$ level of person1 in run-in 1: SD of the four measurements in run-in 1 of person 1.

$\mathrm{SD}_{\text {within }}$ response of person 1: $\mathrm{SD}$ of the two responses for person 1.

$S_{\text {between }}: \sqrt{ }\left(\right.$ SDtotal $\left.^{2}-S^{-S w i t h i n}{ }^{2}\right)$

\section{Results}

We analysed data of 32 subjects, 10 men and 22 women. See table 1 for baseline characteristics. During the study $97 \%$ of the total amount of capsules was consumed. This was determined by counting returned capsules and checking diaries.

\section{Body weight}

There was an average weight change of - $0.4 \mathrm{~kg}$ (range: -3.8 to $+3.8, \mathrm{n}=32$ ) from start to end of the experiment. There was no correlation between changes in weight and the response of serum lipids (data not shown).

\section{Blood lipids}

Table 2 shows the mean responses of serum lipids to coffee oil in periods 1 and 2 . Total cholesterol rose by $24 \%$ (range:0;52\%) in period 1 and by $18 \%(1 ; 48 \%)$ in period 2, LDL cholesterol by $29 \%(-9 ; 71 \%)$ and $20 \%(-12 ; 57 \%)$, triglycerides by $66 \%(16 ; 175 \%)$ and $58 \%(-13 ; 202 \%)$ and HDL cholesterol rose by $3 \%$ in both periods. These changes in HDL levels were not significant. The ranges of 
Table I: Baseline characteristics for all subjects who completed the study

\begin{tabular}{ll}
\hline Characteristic & $(\mathrm{n}=32)$ \\
\hline Age $($ years $)$ & $23 \pm 4$ \\
Height $(\mathrm{m})$ & $1.73 \pm 0.09$ \\
Weight $(\mathrm{kg})$ & $67.4 \pm 10.4$ \\
Body mass index $\left(\mathrm{kg} / \mathrm{m}^{2}\right)$ & $22.4 \pm 3.0$ \\
Serum total cholesterol $(\mathrm{mmol} / \mathrm{l})$ & $4.6 \pm 0.8$ \\
Serum triglycerides $(\mathrm{mmol} / \mathrm{l})$ & $1.00 \pm 0.49$ \\
Alanine aminotransferase $(\mathrm{IU} / \mathrm{l})$ & $25 \pm 7$ \\
Aspartate aminotransferase $(\mathrm{IU} / \mathrm{l})$ & $14 \pm 4$ \\
Current smokers $\mathrm{n}(\%)$ & $7(22)$ \\
Alcohol (glass/week) median $\left(25^{\text {th }}\right.$ percentile, 75 $^{\text {th }}$ percentile) & $3(\mathrm{I}, 7)$ \\
\hline
\end{tabular}

Variables presented as mean $\pm \mathrm{sd}$, current smokers presented as $\mathrm{n}(\%)$.

Table 2: Concentrations of blood lipids during the four study periods

\begin{tabular}{|c|c|c|c|c|}
\hline & Total cholesterol & HDL & LDL & Triglycerides \\
\hline Run-in I (mmol/l) & $4.4 \pm 0.7$ & $1.56 \pm 0.34$ & $2.39 \pm 0.57$ & $1.10 \pm 0.38$ \\
\hline Coffee oil I (mmol/l) & $5.5 \pm 0.9$ & $1.6 \mathrm{I} \pm 0.44$ & $3.08 \pm 0.77$ & $1.82 \pm 0.62$ \\
\hline Run-in 2 (mmol/l) & $4.5 \pm 0.8$ & $1.55 \pm 0.45$ & $2.41 \pm 0.66$ & $1.12 \pm 0.47$ \\
\hline Coffee oil $2(\mathrm{mmol} / \mathrm{l})$ & $5.3 \pm 0.8$ & $1.60 \pm 0.45$ & $2.90 \pm 0.69$ & $1.77 \pm 0.76$ \\
\hline Response I (mmol/l) & $\mathrm{I} . \mathrm{I} \pm 0.5$ & $0.04 \pm 0.18$ & $0.70 \pm 0.40$ & $0.72 \pm 0.40$ \\
\hline Response $2(\mathrm{mmol} / \mathrm{l})$ & $0.8 \pm 0.5$ & $0.05 \pm 0.20$ & $0.49 \pm 0.44$ & $0.65 \pm 0.52$ \\
\hline Correlation between response 1 and 2 & $0.20[-0.16,0.5 I]$ & $0.67[0.42,0.83]$ & $0.16[-0.20,0.48]$ & $0.77[0.56,0.88]$ \\
\hline
\end{tabular}

Values are mean \pm SD The values for each period are means of four samples. Responsel and response 2 are calculated as coffee-oil minus run-in values. Values between brackets are $95 \%$ confidence intervals

the HDL response were $-19 ; 25 \%$ in period 1 and $-20 ; 33 \%$ in period 2.

Individual responses for total and LDL cholesterol in period 2 hardly correlated with those in period 1 . In contrast, individual responses in the two periods for HDL cholesterol (fig. 2) and triglycerides (fig. 3) were highly correlated: the Pearson correlation coefficient was 0.67 for HDL and 0.77 for triglycerides. See table 2 for mean levels and responses.

The total observed standard deviation of the response ( $\mathrm{SD}_{\text {total }}$ response) of serum cholesterol to coffee oil was $0.49 \mathrm{mmol} / \mathrm{l}$. The between subject standard deviation $\left(\mathrm{SD}_{\text {between }}\right)$ of the response of serum cholesterol was 0.22 $\mathrm{mmol} / \mathrm{l}$ and the within subject standard deviation ( $\mathrm{SD}_{\text {within }}$ response) was $0.44 \mathrm{mmol} / \mathrm{l}$. Therefore, a large proportion of the variation in serum cholesterol response to coffee oil was explained by the variation in the response within individuals. The same is true for the LDL response.

The HDL response to coffee oil showed a between subject SD of 0.15 and a within subject SD of $0.11 \mathrm{mmol} / \mathrm{l}$, so the between subject variation was larger than the within subject variation. This explains the high correlation between the two HDL responses.

The triglyceride response showed an SD between individuals of $0.40 \mathrm{mmol} / \mathrm{l}$, which is larger than the within subject SD of $0.22 \mathrm{mmol} / \mathrm{l}$. All standard deviations of serum lipid levels and responses to coffee-oil are presented in Table 3.

Multiple regression analysis showed no association between the response and gender, baseline values, or alcohol use. Only smoking status contributed significantly to the explanation of the variation of the response. However, we did not find a difference in the reproducibility of the serum lipid response to coffee oil between smokers and non-smokers (data not shown).

\section{Liver enzymes}

Eight subjects dropped out in the first period and five in the second period because of ALAT and ASAT levels exceeding the predetermined boundaries. Eleven of these 13 subjects had returned to normal ALAT $(\leq 45 \mathrm{IU} / \mathrm{l})$ and 


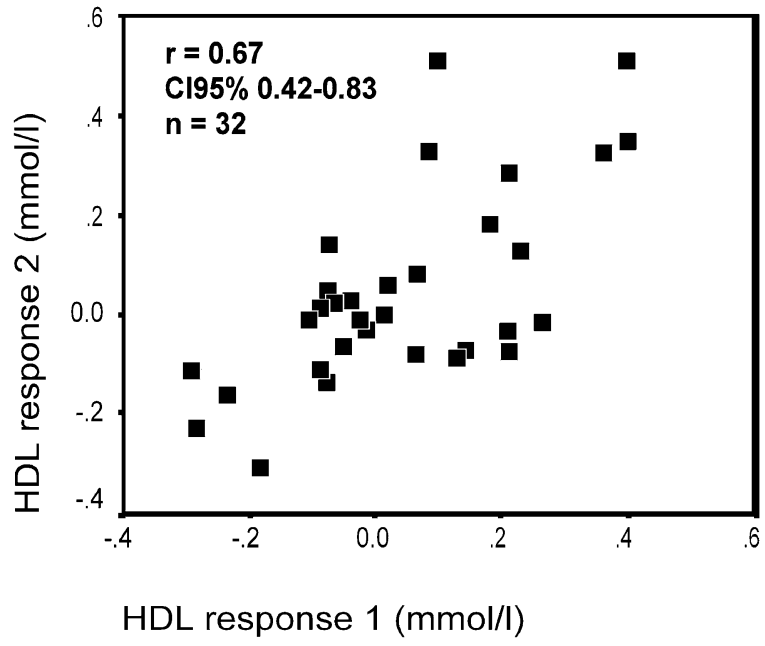

Figure 2

Correlation of HDL response to coffee-oil consumption between period $I$ and 2 . On the $x$-axis the response of coffee-oil in the first period on serum HDL is shown on the $y$-axis the response to coffee-oil in the second period. Each dot represents one subject.
ASAT ( $\leq 41 \mathrm{IU} / \mathrm{l}$ ) levels within two months after exclusion. One subject who had elevated liver enzyme activities after two months was referred to a general practitioner. After another two months her liver enzyme levels were within normal limits again. One subject went abroad before the follow-up measurement.

The ALAT levels of the 32 subjects who finished the study rose on average by $0.51 \pm 0.47$ times the upper limit of normal during the first coffee-oil period and by $0.31 \pm$ 0.29 times the upper limit of normal during the second period. ASAT levels increased by $0.22 \pm 0.20$ times the upper limit of normal during the first period and by 0.15 \pm 0.12 times the upper limit of normal during the second period.

\section{Discussion}

In this study we aimed to establish the reproducibility of the serum-lipid response to coffee oil. We found that the response of total serum cholesterol and LDL to coffee oil was poorly reproducible, whereas the responses of HDL and triglycerides to coffee oil proved to be highly reproducible. A high correlation between two intra-individual responses means that the within-subject variability is relatively low. The between-subject variability of HDL and triglycerides is relatively large. The within-subject reproducibility of the responses of HDL and triglycerides to coffee oil in combination with their large between-sub-

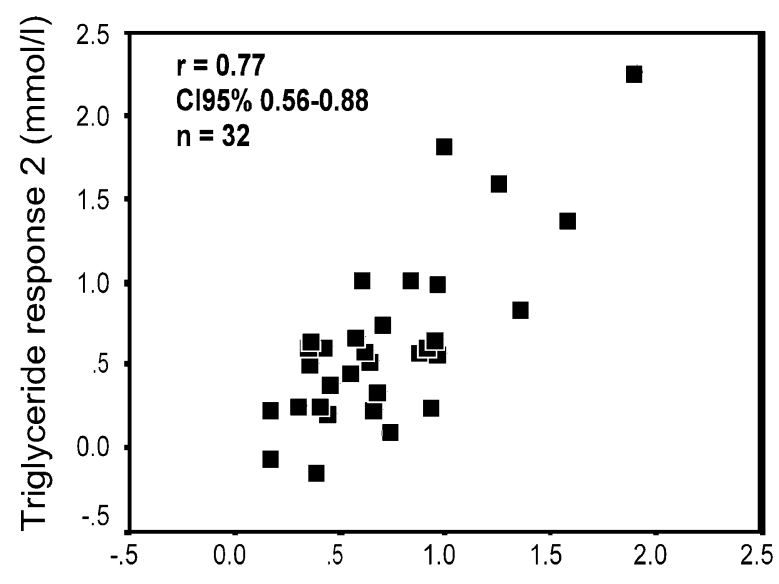

Triglyceride response $1(\mathrm{mmol} / \mathrm{l})$

Figure 3

Correlation of triglyceride response to coffee-oil consumption between period $I$ and 2 . On the $x$-axis the response of coffee-oil in the first period on serum triglycerides is shown on the $y$-axis the response to coffee-oil in the second period. Each dot represents one subject.

ject variability indicates that it is more promising to investigate genetic variation that determines the response of HDL and triglycerides to coffee oil than to investigate the responses of total and LDL cholesterol.

The triglyceride response is relatively large compared to the response of total cholesterol. In our study cholesterol increased on average by $21 \%$ and triglycerides by $62 \%$. It has been shown that cafestol increases plasma triglycerides by an increasing production of a fraction of very low density lipoproteins: $\mathrm{VLDL}_{1}$. The subsequent rise in LDL cholesterol might be caused by enrichement of $\mathrm{VLDL}_{2}$ particles with cholesteryl esters [14].

\section{Group vs. individual response of serum lipids}

The average response to the coffee-oil treatment was similar to that in previous studies at our department [11]. We expected an increase in total serum cholesterol of 1.0 $\mathrm{mmol} / \mathrm{l}$ and an increase of serum triglycerides of 0.65 $\mathrm{mmol} / \mathrm{l}$, which is close to the observed values (Table 2). The coffee oil did not affect the average HDL concentration. Other studies also found either no effect on HDL or a slight decrease in HDL concentrations [11].

The assessment of the individual response of serum lipids is hampered by day-to-day fluctuations in serum lipid levels [3-5]. In this experiment we reduced the effect of these 
Table 3: Standard deviations of levels and responses to cafestol of serum lipids

\begin{tabular}{|c|c|c|c|c|}
\hline & Mean $(\mathrm{mmol} / \mathrm{l})$ & Sdtotal & Sdwithin & Sdbetween \\
\hline \multicolumn{5}{|c|}{ Total cholesterol } \\
\hline Run-in I & 4.45 & 0.72 & 0.26 & 0.67 \\
\hline Coffee-oil I & 5.51 & 0.93 & 0.37 & 0.85 \\
\hline Run-in 2 & 4.47 & 0.79 & 0.26 & 0.75 \\
\hline Coffee-oil 2 & 5.30 & 0.85 & 0.33 & 0.78 \\
\hline Response & 0.95 & 0.49 & 0.44 & 0.22 \\
\hline \multicolumn{5}{|l|}{ HDL } \\
\hline Run-in I & 1.56 & 0.34 & 0.10 & 0.32 \\
\hline Coffee-oil I & 1.61 & 0.44 & 0.12 & 0.42 \\
\hline Run-in 2 & 1.55 & 0.34 & 0.10 & 0.32 \\
\hline Coffee-oil 2 & 1.60 & 0.45 & 0.10 & 0.44 \\
\hline Response & 0.05 & 0.19 & 0.11 & 0.15 \\
\hline \multicolumn{5}{|l|}{ LDL } \\
\hline Run-in I & 2.39 & 0.57 & 0.23 & 0.52 \\
\hline Coffee-oil I & 3.08 & 0.77 & 0.34 & 0.69 \\
\hline Run-in 2 & 2.41 & 0.66 & 0.21 & 0.63 \\
\hline Coffee-oil 2 & 2.90 & 0.69 & 0.33 & 0.61 \\
\hline Response & 0.60 & 0.42 & 0.39 & 0.16 \\
\hline \multicolumn{5}{|c|}{ Triglycerides } \\
\hline Run-in I & 1.10 & 0.38 & 0.23 & 0.30 \\
\hline Coffee-oil I & 1.82 & 0.62 & 0.39 & 0.48 \\
\hline Run-in 2 & 1.12 & 0.47 & 0.22 & 0.42 \\
\hline Coffee-oil 2 & $\mathrm{I} .77$ & 0.76 & 0.42 & 0.63 \\
\hline Response & 0.69 & 0.46 & 0.22 & 0.40 \\
\hline
\end{tabular}

fluctuations by using the mean of four separate measurements $[15,16]$.

Analyses of the between and within-person standard deviations (SD's) of the responses of serum lipids to coffee oil confirm that total cholesterol and LDL responses are poorly reproducible. The SD's of the responses of total cholesterol and LDL had a within-person component that was clearly larger than the between-person component. For the total cholesterol response to coffee oil we found a total SD of $0.49 \mathrm{mmol} / \mathrm{l}$, an $\mathrm{SD}_{\text {within }}$ of $0.44 \mathrm{mmol} / \mathrm{l}$, and an $\mathrm{SD}_{\text {between }}$ of $0.22 \mathrm{mmol} / \mathrm{l}$. This is at variance with the results of Katan et al who observed an SD of $0.33 \mathrm{mmol} / \mathrm{l}$, an $\mathrm{SD}_{\text {within }}$ of $0.16 \mathrm{mmol} / \mathrm{l}$, and an $\mathrm{SD}_{\text {between }}$ of 0.29 $\mathrm{mmol} / \mathrm{l}$ for total cholesterol [2]. This would indicate a better reproducibility than observed in our study. However, Katan et al selected putative hyperresponders and hyporesponders which will lead to overestimation of the reproducibility. In our study the response of triglycerides shows a large SD between individuals and a quite small SD within persons. This confirms that the response varies between individuals and that the response is reproducible within persons.
We did not separate laboratory variation in our model for calculation of SD's. We estimated this variation by measuring serum lipids in 32 duplo samples. Coefficients of variation were $1.6 \%$ for total cholesterol, $1.8 \%$ for HDL, and $2.3 \%$ for triglycerides. This means that the laboratory variation is so small that it can be omitted from the model without affecting the calculated values of $\mathrm{SD}_{\text {within }}$ and $\mathrm{SD}_{\text {between }}$.

\section{Study limitations}

Although cafestol is a potent cholesterol-raising food component, it is not certain that it can be used for the study of variation in genes regulating the serum-lipid response to other foods. It is possible that cafestol regulates different genes than other food components such as dietary cholesterol or saturated fats do. Furthermore, we did not use pure cafestol in this study, but coffee oil, which contains many more components, such as triglycerides, free fatty acids, and sterols. However, coffee-oil stripped of diterpenes has no effect on serum lipids [9]. Therefore, genes that cause a rise in serum cholesterol are probably affected by diterpenes. 
Another limitation of the study is that the subjects were free living and did not receive a controlled diet. Therefore, the response of serum lipids to the coffee oil could be changed by other factors. We instructed the subjects to maintain dietary habits, smoking habits, and physical activity. Changes were recorded in a diary together with use of medication and illness. According to the diaries, subjects maintained their habitual lifestyle. Furthermore, coffee oil has such a large effect on serum-lipid levels that small effects of other factors are not of great concern.

A fourth limitation is the large drop out due to elevations of liver enzymes. There was, however, no correlation between the rise in serum-lipid levels and the rise in liver enzymes (data not shown). Therefore, there is no reason to assume that the reproducibility of the serum lipid response to coffee oil in subjects who showed a considerable increase of liver enzymes differs from the serum lipid response in subjects who did not show a large increase of liver enzymes.

On basis of this study it can not be concluded with certainty that a response to coffee oil that differs between individuals but is reproducible within individuals is determined by genetic variation.

\section{Liver enzymes}

Levels of the liver enzymes ALAT and ASAT rose after administrating coffee oil, as was expected from previous studies $[9,11,12,17]$. The rises in ALAT and ASAT indicate that coffee oil can cause acute injury to hepatocytes $[18,19]$. Alcohol, being hepatotoxic, might be an important cofactor in this effect [20]. In this study no association between use of alcohol and drop out due to elevation of liver enzymes was observed. Levels of ALAT rose more than ASAT levels did. This could mean that the membranes of hepatocytes were damaged $[18,20]$.

\section{Genetic factors underlying the serum lipid response to cafestol}

Given the ratio of between and within person variability of the responses of HDL and triglycerides to coffee oil, research into genetic determinants of the response seems to be feasible.

Other studies have described polymorphisms in genes that have a small effect on the total-cholesterol response to cafestol and dietary fat [6-8]. An example is the cholesteryl ester transfer protein (CETP). CETP is a protein that mediates the transfer of cholesteryl esters from HDL to LDL and VLDL. Cafestol, like dietary cholesterol and fat, might increase the transfer of cholesteryl esters by increasing the activity of CETP. Weggemans et al. showed that humans with the CETP Taqlb-1/2 allele have a smaller response of LDL to cafestol, or dietary fat and cholesterol
[21]. However, it remains to be established whether CETP has a role in the cholesterol-raising effect of cafestol and whether a polymorphism in the gene accounts for some of the variation in response between individuals.

Other candidate genes are genes encoding for proteins in the bile acid metabolism. Cholesterol is converted to bile acids in the liver. There are two pathways involved: the neutral and the acidic pathway. The rate-limiting enzyme in the neutral pathway is $7 \alpha$-hydroxylase, which is regulated by bile acids through a negative feedback mechanism [22]. Chenodeoxycholic acid (CDCA), a primary bile acid, suppresses $7 \alpha$-hydroxylase activity by binding directly to the farnesoid $\mathrm{X}$ receptor $[23,24]$. It has been shown in mice that cafestol inhibits bile acid synthesis, which could cause the rise in serum cholesterol [25]. If functional polymorphisms are present in the genes involved in bile acid metabolism, these could be responsible for the variation in the conversion of cholesterol to bile acids. Therefore, it is interesting to study whether cafestol regulates genes involved in bile-acid metabolism.

Polymorphisms in the genes of the pathways mentioned above could account for the variation in response to cafestol between individuals. There are more possible candidates, such as sterol regulatory element binding proteins, microsomal triglyceride transfer protein, lecithin:cholesterol acyltransferase, lipoprotein lipase, and hepatic lipase.

In this study the responses of HDL and triglycerides to coffee oil showed a sufficient reproducibility. Therefore, our best option is to focus on these serum lipids and characterize an individual's response to coffee oil by the HDL and triglyceride response in future research. The variation between persons in the response of HDL and triglycerides combined with the consistency within persons does not guarantee that a large genetic effect is present. It means that environmental determinants of the response were stable within individuals during the time span of the study, whereas there were differences between individuals in other environmental determinants and/or genetic determinants. The question remains whether possible genetic effects are large enough to be detected and whether variation in these genes is sufficiently prevalent in the population.

Clarification of the mechanism by which cafestol increases serum lipids might provide leads for dietary and pharmacotherapeutical ways to lower serum cholesterol. The 'cafestol model' also could be a trial case for evaluating the possibility of personalized diets. If it is possible to predict people's serum-lipid responses to cafestol on basis of their genetic make-up and to make dietary 
recommendations based on this genetic information, this could also be applicable in other situations.

\section{Author's contributions}

MVB participated in designing and planning the study, headed the investigation during the intervention period, analysed the data and wrote the paper together with MFE, who also contributed to the data analysis. MBK initiated the project and raised the funds. EGS was the senior scientist supervising the project.

\section{Acknowledgements}

This study was sponsored by the Dutch organisation of scientific research (NWO) and the Wageningen Centre for Food Sciences (WCFS). We are indebted to the volunteers who participated in this study. We also like to thank Dr M Blanc of Nestlé for providing the coffee oil. Furthermore we would like to thank all the dieticians, laboratory personnel and students involved in this project.

\section{References}

I. Beynen AC and Katan MB: Reproducibility of the variations between humans in the response of serum cholesterol to cessation of egg consumption. Atherosclerosis |985, 57(I):|9-3|.

2. Katan MB, Beynen AC, De Vries JH and Nobels A: Existence of consistent hypo- and hyperresponders to dietary cholesterol in man. Am J Epidemiol 1986, I 23(2):22I-34.

3. Katan MB and Beynen AC: Characteristics of human hypo- and hyperresponders to dietary cholesterol. Am J Epidemiol 1987, I 25(3):387-99.

4. Beynen AC, Katan MB and Van Zutphen LF: Hypo- and hyperresponders: individual differences in the response of serum cholesterol concentrations to changes in diet. Adv Lipid Res 1987, 22: ||5-7|.

5. Katan MB, Van Gastel AC, De Rover CM, Van Montfort MA and Knuiman JT: Differences in individual responsiveness of serum cholesterol to fat-modified diets in man. Eur J Clin Invest 1988, 1 8(6):644-7.

6. Ordovas JM, Lopez-Miranda J, Mata P, Perez-Jimenez F, Lichtenstein $\mathrm{AH}$ and Schaefer $\mathrm{E}$ ): Gene-diet interactions in determining plasma lipid response to dietary intervention. Atherosclerosis 1995, Suppl I I 8:SII-S27.

7. Ordovas JM and Schaefer E): Genes, variation of cholesterol and fat intake and serum lipids. Curr Opin Lipidol 1999, 10:15-22.

8. Clifton PM and Abbey M: Genetic control of response to dietary fat and cholesterol. World Rev Nutr Diet 1997, 80: I-I4.

9. Weusten-van der Wouw MP, Katan MB, Viani R, Huggett AC, Liardon $\mathrm{R}$ and Liardon R: Identity of the cholesterol-raising factor from boiled coffee and its effects on liver function enzymes. J Lipid Res 1994, 35:72I-33.

10. Urgert R, Van der Weg G, Kosmeijer-Schuil TG, Van den Bovenkamp $\mathrm{P}$ and Hovenier R: Levels of the cholesterol-elevating diterpenes cafestol and kahweol in various coffee brews. J Agric Food Chem 1995, 43:2167-72.

II. Urgert R and Katan MB: The cholesterol-raising factor from coffee beans. Annu Rev Nutr 1997, 17:305-24.

12. Urgert R, Essed N, Van der Weg G, Kosmeijer-Schuil TG and Katan $M B$ : Separate effects of the coffee diterpenes cafestol and kahweol on serum lipids and liver aminotransferases. Am J Clin Nutr 1997, 65(2):519-24.

13. Friedewald WT, Levy RI and Fredrickson DS: Estimation of the concentration of low-density lipoprotein cholesterol in plasma, without use of the preparative ultracentrifuge. Clin Chem 1972, I 8(6):499-502.

14. de Roos B, Caslake MJ, Stalenhoef AF, Bedford D, Demacker PN, Katan $M B$ and Packard $C$ J: The coffee diterpene cafestol increases plasma triacylglycerol by increasing the production rate of large VLDL apolipoprotein B in healthy normolipidemic subjects. Am J Clin Nutr 200I, 73(I):45-52.
15. Cooper GR, Myers GL, Smith SJ and Sampson EJ: Standardization of lipid, lipoprotein and apolipoprotein measurements. Clin Chem I988, 34(8B):B95-105.

16. Cooper GR, Myers GL, Smith SJ and Schlant RC: Blood lipid measurements: Variations and practical utility. JAMA 1992, 267(12):1652-60.

17. Urgert R, Schulz AG and Katan MB: Effects of cafestol and kahweol from coffee grounds on serum lipids and serum liver enzymes in humans. Am J Clin Nutr 1995, 61(1):149-54.

18. Keil R: Determination of enzyme activities in serum for the detection of xenobiotic effects on the liver. Exp Pathol 1990, 39:157-64.

19. Herrera JL: Abnormal liver enzyme levels. The spectrum of causes. Postgrad Med 1993, 93(2): 1 13-6.

20. Sherman KE: Alanine amintransferase in clinical practice. A review. Arch Intern Med I99I, I 5 I(2):260-5.

21. Weggemans RM, Zock PL, Ordovas JM, Ramos-Galluzi J and Katan MB: Genetic polymorphisms and lipid response to dietary changes in humans. Eur J Clin Invest 200 I, 3 I (I I):950-957.

22. Princen HM, Post SM and Twisk J: Regulation of bile acid synthesis. Curr Pharmaceut Design 1997, 3(1):59-84.

23. Tu $H$, Okamoto $A Y$ and Shan $B$ : FXR, a bile acid receptor and biological sensor. Trends Cardiovasc Med 2000, I O(I):30-5.

24. Chawla A, Repa JJ, Evans RM and Mangseldorf DJ: Nuclear receptors and lipid physiology: Opening the $\mathbf{X}$-files. Science 200I, 294(5548): 1866-70.

25. Post SM, de Roos B, Vermeulen M, Afman L, Jong MC and Dahlmans VE: Cafestol increases serum cholesterol levels in apolipoprotein $E * 3-$-Leiden transgenic mice by suppression of bile acid synthesis. Arterioscler Thromb Vasc Biol 2000, 20(6): I55 I-6.
Publish with Bio Med Central and every scientist can read your work free of charge

"BioMed Central will be the most significant development for disseminating the results of biomedical research in our lifetime. "

Sir Paul Nurse, Cancer Research UK

Your research papers will be:

- available free of charge to the entire biomedical community

- peer reviewed and published immediately upon acceptance

- cited in PubMed and archived on PubMed Central

- yours - you keep the copyright

Submit your manuscript here:

http://www.biomedcentral.com/info/publishing_adv.asp
BioMedcentral 